\title{
Inpatient management of diabetes mellitus with poor glycaemic control: determinants of therapeutic
} \section{success}

\begin{abstract}
Background: Education is an obligatory part of diabetes management and treatment. A significant part of the inadequate control of this globally disease is due to a failure in the transmission by health care providers of the necessary knowledge for patients with diabetes be active in self-care. The inpatient setting provides the perfect environment to focus on a continuous and daily education, approaching the various dimensions of diabetes. However, it remains to be clarified whether the potential benefits of this strategy can outweigh the high costs associated with an elective hospitalisation. The aim of this study was to clarify the determinants of therapeutic success of patients with diabetes mellitus with poor glycaemic control admitted electively.
\end{abstract}

Methods: It was conducted a retrospective study of a 66-patient-cohort electively admitted for diabetes management. The patients maintained endocrinology ambulatory follow-up after discharge. We defined as poor glycaemic control the presence of sustained hyperglycaemia or marked glycaemic variability despite several attempts at therapeutic optimization in the outpatient setting. Therapeutic success was defined as a $\mathrm{HbA} 1 \mathrm{c}$ reduction of $\geq 1.5 \%$ at 12 -months of follow- up. The impact of clinical and biochemical parameters on therapeutic success was explored through bivariate logistic regression models.

Results: Therapeutic success was achieved in $48.5 \%$ of patients. The majority of patients with type 1 diabetes $(77.8 \%)$ had no therapeutic success, while the majority of patients with type 2 diabetes $(61.4 \%)$ showed significant improvement $(p<0.05)$. The therapeutic failure group had more previous years of insulin therapy (10.0 [IQR $5.0-20.5]$ vs $4.0[1.0-10.0]$ years; $p=0.001)$, more patients with neuropathy $(38.2 \%$ vs $15.6 \%, \mathrm{p}=0.039)$ and diabetic foot lesions $(35.3 \%$ vs $3.1 \%, \mathrm{p}=0.001)$. In contrast, the therapeutic success group had more patients presenting with dyslipidaemia $(90.6 \%$ vs $67.6 \%, p=0.022)$. All patients not previously treated with insulin succeeded, while $65.6 \%$ of patients under intensive insulin therapy evolved to therapeutic failure $(\mathrm{p}<0.05)$. In a binary logistic regression model only baseline HbAlc and previous diagnosis of dyslipidaemia were significant predictors of therapeutic success. Baseline HbAlc showed a good discriminating power $(\mathrm{AUC}=0.806$; 95\%CI 0.702 $0.909 ; \mathrm{p}<0.001)$.

Conclusion: HbA1c value can forecast therapeutic success of inpatient diabetes management.

Keywords: Diabetes mellitus, glycaemic control, therapeutic success, inpatient care
Volume 6 Issue $5-2018$

\author{
Daniela Magalhaes, ${ }^{1,2,3}$ Ines Furtado, ${ }^{4}$ Ana \\ Saavedra, ${ }^{1,2,3}$ Rita Bettencourt-Silva, ${ }^{1,2,3}$ Maria \\ M Costa, ${ }^{1,2,3}$ Faceira A, ${ }^{2,5}$ Claudia Nogueira, ${ }^{6}$ \\ Joana Queiros,' Jose L Castedo,' Paula \\ Freitas, ${ }^{1,2,3}$ Davide Carvalho, ${ }^{1,2,3}$ \\ 'Endocrinology, Diabetes and Metabolism Department of \\ Centro Hospitalar de Sao Joao EPE, Portugal \\ ${ }^{2}$ Faculty of Medicine of University of Porto, Portugal \\ ${ }^{3}$ Instituto de Investigacao e Inovacao em Saude, University of \\ Porto, Portugal \\ ${ }^{4}$ Internal Medicine Department of Centro Hospitalar do Porto, \\ Portugal \\ ${ }^{5}$ Internal Medicine Department of Centro Hospitalar de Sao \\ Joao EPE, Portugal \\ ${ }^{6}$ Endocrinology Department of Centro Hospitalar de Tras-os- \\ Montes e Alto Douro EPE, Portugal
}

Correspondence: Daniela Magalhaes, Endocrinology, Diabetes and Metabolism Department of Centro Hospitalar de Sao Joao EPE, Alameda Prof, Hernani Monteiro, 4200-319-Porto, Portugal, Tel +35196488I569, Email danielascmagalhals@gmail.com

Received:September 26, 20I8 | Published: October 3I, 2018
Abbreviations: DM, diabetes mellitus; BMI, body mass index; SBP, systolic blood pressure; DBP, diastolic blood pressure; AUC, area under the curve; T1DM, type 1 diabetes mellitus; T 2 D M , type 2 diabetes mellitus; OR, odds ratio; CI, confidence interval; IQR, interquartil range; HBP, high blood pressure; $\mathrm{ACEi}$, angiotensinconverting-enzyme inhibitor; ARB, angiotensin receptor blocker; $\mathrm{BB}$, beta blockers; CCB, calcium channel blockers; OSA, obstructive sleep apnea; HF, heart failure; AST, aspartate aminotransferase; ALT, alanine aminotransferase; $\quad$ GGT, $\gamma$ - glutamyltransferase; AF, alkaline phosphatase; LDL-C, low density protein cholesterol; HDL-C, high density lipoprotein cholesterol; TG, Triglycerides: $\mathrm{HbAlc}$, glycated haemoglobin; UAE, urinary albumin excretion

\section{Background}

Diabetes mellitus (DM) is a chronic disease with an increasing prevalence worldwide, involving both sexes and all ages. In 2015, the estimated prevalence of DM in the Portuguese population aged between 20 and 79 years (7.7 million individuals) was $13.3 \%$, namely more than 1 million.

Moreover, $5.8 \%$ were previously unaware of the diagnosis. Globally, and in the same year, it was estimated that 415 million people, one in every 11 adults, suffered from DM. ${ }^{1}$

The increasing incidence of DM and prediabetes represents a leading public health problem, concerning the entire medical community and health care systems around the world. Every day, endocrinologists face the challenge of trying to condense a large volume of complex information and practical skills into something useful for a population that is often illiterate and scarce in their abilities. The high number of consults and the reduced time for individual evaluation often makes it difficult to overcome.

When attempts to educate patients about their disease, self-care 
and treatment in an outpatient setting don't reach the goals for disease control, physicians sometimes chose management in an inpatient setting. With the patient hospitalised a daily and continuous education is possible, focusing on the doubts and fears of the patient regarding the disease and its complications.

Furthermore, the physicians can monitor and reinforce the selfmonitoring of blood glucose, as well the insulin self-administration technique. It is at this stage that some mistakes are often identified, commonly not perceived by the patient, which make it impossible to control the disease effectively. However, the hospitalisation of patients with DM, with the aim of educating and modifying therapeutic schemes, inevitably contributes to increasing health costs. In 2015, the direct cost of DM was estimated between 1.3 and 1.55 million Euros, which represents $8-10 \%$ of all health expenditure in Portugal. ${ }^{1}$ Although hospitalisation seems to be a useful strategy for patients with diabetes, it is expensive.

The aim of this study was to understand the efficacy of inpatient DM management in terms of metabolic control improvement, trying to identify the determinants of therapeutic success of elective hospital admission of patients with DM and poor glycaemic control.

\section{Methods}

\section{Study design and participants}

A retrospective cross-sectional study was conducted in a population of patients with diabetes evaluated in the Endocrinology ambulatory centre of Centro Hospitalar de São João in Portugal. A total of 86 patients were electively admitted with DM and poor glycaemic control in the Endocrinology department between January 2014 and December 2015. We defined as poor glycaemic control the presence of sustained hyperglycaemia or marked glycaemic variability despite several attempts at therapeutic optimization in the outpatient setting. Once admitted, we tried to focus on diabetes education on a daily basis, reviewing the techniques of glycaemic self- monitoring and insulin administration, as well the information needed to adopt a healthier lifestyle and a structured eating plan adjusted to each patient's individual comorbidities. The inpatient treatment consisted in initiating insulin therapy in those who, despite optimized oral antidiabetic therapy, maintained poor glycaemic control, as well as in the adjustment of insulin therapy in those previously treated with insulin, in some with simple dose adjustment and in others with the change of the type of insulin or the transition to multiple doses injection therapy. Oral antidiabetic therapy was maintained where appropriate. Patients were discharged when sustained improvement in glycaemic control was observed, without hypoglycaemia. Of the 86 patients, 66 maintained follow-up in the endocrinology ambulatory centre after discharge and were enrolled in this study.

Demographic data (age and sex), medical history (history of DM and its complications and comorbidities), clinical and anthropometric features (body mass index [BMI], systolic and diastolic blood pressures [SBP and DBP]) and analytic measures (liver function tests, lipid profile, fasting plasma glucose and $\mathrm{HbA1c}$, serum creatinine and urinary albumin excretion) were obtained up to three months before hospital admission and at 12-month of follow-up after discharge. Therapeutic success was defined as a HbAlc reduction of at least $1.5 \%$ at 12 -month of follow-up.

\section{Statistical analysis}

Categorical variables were expressed as frequencies and percentages, and these were compared by chi-square test. Continuous variables were presented as means or medians, with their respective measures of dispersion, standard deviation or percentiles, depending on whether they followed a normal or non-normal distribution, respectively. Normal distribution was evaluated using Shapiro-Wilk test or skewness and kurtosis. The parametric continuous variables were compared using Student's t-test and the non-parametric continuous variables using the Mann Whitney or Wilcoxon tests, depending on whether these were independent or matched groups, respectively. Independent predictors of therapeutic success were identified by binary logistic regression and their predictive performance was measured with the area under the curve (AUC) of the receiver operating characteristic (ROC) curve. Reported $\mathrm{p}$ values were two-tailed, and $p<0.05$ was considered significant. Analyses were performed using SPSS Statistics $20 \AA$.

\section{Results}

\section{Baseline characteristics}

Of the 66 patients enrolled in the study 32 (48.5\%) achieved therapeutic success and $34(51.5 \%)$ were classified as therapeutic failure. The comparison of baseline demographic and past medical history characteristics between patients that achieved therapeutic success and those who did not is shown in Table 1. These two groups were similar in distribution by sex and age. The majority of patients with type 1 diabetes (T1DM) (77.8\%) didn't have therapeutic success, while the majority of patients with type 2 diabetes (T2DM) $(61.4 \%)$ achieved therapeutic success $(\mathrm{p}<0.05)$. T2DM patients, in contrast with T1DM patients, appear to have a chance of therapeutic success of 5.6:1 (OR=5.6; 95\% CI 1.57-19.72; $\mathrm{p}=0.008)$. The authors found that patients with therapeutic failure had more previous years of insulin therapy (10.0 [IQR 5.0-20.5] vs 4.0 [1.0-10.0] years; $\mathrm{p}=0.001)$ and that for each additional year of insulin therapy there appears to be a $10 \%$ decrease in the chance of therapeutic success $(\mathrm{OR}=0.9$; $95 \%$ CI $0.82-0.96 ; p=0.003)$. Regarding the presence of micro- and macrovascular complications of DM, the presence of neuropathy was significantly higher in patients with therapeutic failure $(38.2 \%$ vs $15.6 \%, \mathrm{p}=0.039$ ) and was associated with a $70 \%$ reduction in the likelihood of therapeutic success $(\mathrm{OR}=0.3$; 95\% CI $0.09-0.97$; $\mathrm{p}=0.045)$. On the other hand, the majority of patients without diabetic foot lesion history $(58.5 \%)$ achieved therapeutic success, in contrast with patients with diabetic foot complications (treatment failure in $92.3 \%$ ). The presence of foot lesions or deformities seems to reduce the chance of therapeutic success by $94 \%(\mathrm{OR}=0.06$; $95 \% \mathrm{CI} 0.007$ $0.489 ; \mathrm{p}=0.009)$. Regarding cardiovascular comorbidities related to $\mathrm{DM}$, we found a greater number of patients presenting with dyslipidaemia in the therapeutic success group $(90.6 \%$ vs $67.6 \%$, $\mathrm{p}=0.022$ ). The presence of dyslipidaemia seems to be associated with a possibility of success about 4.6 times higher (OR 4.6; 95\%CI $1.15-18.54 ; \mathrm{p}=0.031)$. Concerning the therapy at the time of hospital admission, all patients not previously treated with insulin that initiated insulin therapy during the hospital stay, had therapeutic success. In contrast, the majority $(65.6 \%)$ of patients previously treated with multiple dose insulin injection had therapeutic failure.

The comparison of clinical and biochemical features between patients who achieved therapeutic success and those who did not is shown in Table 2. The two groups were found to be similar in most of the evaluated parameters, with the exception of triglycerides and $\mathrm{HbA1c}$ values, both significantly higher in the group of patients who achieved therapeutic success. 
Table I Comparison of baseline demographic and pathological features between patients with and without therapeutic success

\begin{tabular}{|c|c|c|c|}
\hline $\mathrm{HbAl}$ c reduction $\geq \mathrm{I} .5 \%$ & Therapeutic success $(\mathbf{N}=32)$ & Therapeutic failure $(\mathbf{N}=\mathbf{3 4})$ & $p$ \\
\hline Sex (F/M), n(\%) & $24(75) / 8(25)$ & $20(58.8) / \mid 4(4 \mid .2)$ & 0.164 \\
\hline Age (years) & 60 (IQR 52-69) & 60.5 (IQR 48-63) & 0.264 \\
\hline Type of DM (I/2/Others), n (\%) & $4(12.5) / 27(84.4) / /(3.1 \%)$ & I4 (4I.2)/I7 (50)/3 (8.8) & $0.010 *$ \\
\hline Length of hospital stay (days) & 7 (IQR 6-8) & 6 (IQR 5-7) & 0.054 \\
\hline Years of diagnosis & $14(10-20)$ & $19(10-23)$ & 0.125 \\
\hline Years of insulin therapy & $4.0(1.0-10.0)$ & $10.0(5.0-20.5)$ & $0.001 *$ \\
\hline Cause of decompensation, $\mathrm{n}$ (\%) & & & 0.325 \\
\hline Therapeutic noncompliance & $14(43.8)$ & $19(55.9)$ & \\
\hline Infection & 0 & 0 & \\
\hline Metabolic decompensation & I8.0 (56.3) & I5.0 (44.I) & \\
\hline \multicolumn{4}{|l|}{ Target organ damage, n (\%) } \\
\hline Retinopathy & $13(40.6)$ & $2 I(6 I .8)$ & 0.086 \\
\hline Nephropathy & $17(53.1)$ & $13(38.2)$ & 0.225 \\
\hline Neuropathy & $5(15.6)$ & $13(38.2)$ & $0.039 *$ \\
\hline Coronary artery disease & $7(21.9)$ & $2(5.9)$ & 0.079 \\
\hline Cerebrovascular disease & $10(31.3)$ & $8(23.5)$ & 0.482 \\
\hline Peripheral arterial disease & $2(6.3)$ & $4(11.8)$ & 0.673 \\
\hline Diabetic foot & & & $0.002 *$ \\
\hline Grade 0 & $3 I(96.9)$ & $22(64.7)$ & \\
\hline Grade I & $0(0)$ & $2(5.9)$ & \\
\hline Grade 2 & $I(3.1)$ & $4(11.8)$ & \\
\hline Grade 3 & $0(0)$ & $6(17.6)$ & \\
\hline HBP, n (\%) & $26(8 \mid .2)$ & $33(97.1)$ & 0.051 \\
\hline ACEi/ARB & $22(68.8)$ & $23(67.6)$ & \\
\hline BB & $10(31.3)$ & II(32.4) & \\
\hline $\mathrm{CCB}$ & $9(28.1)$ & $12(35.3)$ & \\
\hline Thiazide diuretics & $12(37.5)$ & $7(20.6)$ & \\
\hline Loop diuretics & $4(12.5)$ & $5(14.7)$ & \\
\hline Dyslipidaemia & $29(90.6)$ & $23(67.6)$ & $0.022 *$ \\
\hline Statin & $24(75.0)$ & $22(64.7)$ & 0.428 \\
\hline Fibrate & $8(25.0)$ & $8(23.5)$ & 1.00 \\
\hline Smoking habits, n (\%) & $I(3 . I)$ & $4(11.8)$ & 0.357 \\
\hline Overweight, n (\%) & $9(28.1)$ & $8(23.5)$ & 0.67 \\
\hline Obesity (grades), n (\%) & & & 0.324 \\
\hline 1 & $5(15.6)$ & $7(20.6)$ & \\
\hline 2 & $6(18.8)$ & $3(8.8)$ & \\
\hline 3 & $2(6.3)$ & 0 & \\
\hline OSA, n (\%) & $\mathrm{I}(3 . \mathrm{I})$ & I (2.9) & 1.000 \\
\hline Hepatic steatosis, n (\%) & $5(15.6)$ & $5(14.7)$ & 1.000 \\
\hline HF, n (\%) & $2(6.3)$ & $5(14.7)$ & 0.428 \\
\hline Osteoarticular disease, n (\%) & $9(28.1)$ & $6(17.6)$ & 0.31 \\
\hline Depressive syndrome, n (\%) & $8(25.0)$ & $4(11.8)$ & 0.164 \\
\hline
\end{tabular}


Table Continued...

\begin{tabular}{llll}
\hline HbA I c reduction $\geq \mathbf{I . 5 \%}$ & Therapeutic success $(\mathbf{N}=\mathbf{3 2})$ & Therapeutic failure $(\mathbf{N}=\mathbf{3 4})$ & $\mathbf{P}$ \\
\hline $\begin{array}{l}\text { Neoplasms, } \mathrm{n}(\%) \\
\text { Insulin therapy, } \mathrm{n}(\%)\end{array}$ & $\mathrm{I}(3 . \mathrm{I})$ & $5(14.7)$ & 0.198 \\
No insulin & & & $0.029 *$ \\
Basal & $5(15.6)$ & $0(0)$ \\
Basal-Bolus & $\mathrm{II}(34.4)$ & $8(23.5)$ \\
Pre-mixed & $\mathrm{II}(34.4)$ & $21(61.8)$ \\
Carbohydrate counting & $5(15.5)$ & $4(11.8)$ & \\
\hline
\end{tabular}

Abbreviations: IQR, interquartil range; $\mathrm{HBP}$, high blood pressure; $\mathrm{ACE}$, angiotensin-converting-enzyme inhibitor; $\mathrm{ARB}$, angiotensin receptor blocker; $\mathrm{BB}$, beta blockers; CCB, calcium channel blockers, OSA; obstructive sleep apnea, HF, heart failure.

*Statistically significant $(\mathrm{p}<0.05)$.

Table 2 Comparison of clinical and biochemical features at baseline between patients with and without therapeutic success

\begin{tabular}{|c|c|c|c|}
\hline $\mathrm{HbAl}$ c reduction $\geq \mathrm{I} .5 \%$ & Therapeutic success & Therapeutic failure & $p$ \\
\hline IBMI $\left(\mathrm{kg} / \mathrm{m}^{2}\right)$ & $30.3 \pm 6.1$ & $27.9 \pm 5.4$ & 0.712 \\
\hline SBP $(\mathrm{mmHg})$ & $128.8 \pm 22.6$ & $130.1 \pm 18.9$ & 0.354 \\
\hline $\mathrm{DBP}(\mathrm{mmHg})$ & $73.7 \pm 12.5$ & $74.1 \pm 13.1$ & 0.88 \\
\hline AST (VR: I0-3। U/L) & 23.0 (IQR I8.5-34.5) & 19.0(IQR I7.0-37.0) & 0.277 \\
\hline ALT (VR: I0-3। U/L) & 28.5 (IQR I6.0-44.0) & I6.5(IQR I3.5-36.0) & 0.163 \\
\hline GGT (VR: 7-3IU/L) & 48.0 (IQR 23.5-78.5) & 27.5(IRQ I6.0-5I.0) & 0.058 \\
\hline AF (VR: 30-I20 U/L) & $99.0 \pm 42.5$ & $90.5 \pm 36.9$ & 0.394 \\
\hline Total cholesterol (mg/dL) & I55 (IQR I40.0-207.0) & I53.0 (IQR I38.0-177.0) & 0.367 \\
\hline HDL-C (mg/dL) & $45.8 \pm 11.2$ & $50.4 \pm \mid 4.2$ & 0.193 \\
\hline LDL-C (mg/dL) & 91 (IQR 72.5- I22.5) & 78 (IQR 63.0-99.0) & 0.148 \\
\hline TG (mg/dL) & I5I(IQR I28.0-227.0) & II8(IQR 78.0-169.0) & $0.022 *$ \\
\hline FPG (mg/dL) & 207 (IQR I34.5-263.5) & | $4 \mid .0$ (IQR | | $0.0-197.0)$ & 0.054 \\
\hline HbAlc (\%) & II.I (IQR I0.2-13.0) & 9.8(IRQ 9.0-10.5) & $<0.001 *$ \\
\hline Serum creatinine $(\mathrm{mg} / \mathrm{dL})$ & 0.73 (IQR 0.63-I.23) & 0.75 (IQR 0.63-I.23) & 0.849 \\
\hline UAE (mg/L) & 35.4 (IQR 4.8-84.7) & I0.9 (IQR 4.4-69.0) & 0.449 \\
\hline
\end{tabular}

Abbreviations: IQR, interquartil range; BMI, body mass index; SBP, systolic blood pressure; DPB, diastolic blood pressure; AST, aspartate aminotransferase; ALT, alanine aminotransferase; GGT, $\gamma$ - glutamyltransferase; AF, alkaline phosphatase; LDL-C, low density protein cholesterol; HDL-C, high density lipoprotein cholesterol;TG, triglycerides; HbAIc, glycated haemoglobin; UAE, urinary albumin excretion.

*Statistically significant $(\mathrm{p}<0.05)$

\section{Ambulatory follow-up}

Clinical and biochemical features were reassessed at 12 months after hospital discharge and were compared with the baseline values within the same group. A comparison between groups was also performed. These results are shown in Table 3. In the group of patients with therapeutic success, there was no improvement of metabolic parameters evaluated (other than $\mathrm{HbAlc}$ ). On the other hand, in the group of patients with therapeutic failure, there was a significant increase 199 in BMI $(27.9 \pm 5.4$ to $29.1 \pm 5.3 \mathrm{~kg} / \mathrm{m} 2, \mathrm{p}<0.001)$ and SBP $(130.1 \pm 18.9$ to $140.5 \pm 26.2 \mathrm{mmHg}, \mathrm{p}=0.038)$. Paradoxically, we found a significant increase in HDL-cholesterol (47.0 [IQR 42.0$58.0]$ to 57.0 [IQR 46.0-62.0], $\mathrm{p}=0.013$ ), which median value turns to be significantly higher $(\mathrm{p}=0.002)$ than the one in patients with therapeutic success at 12 months follow-up.

Table 3 Comparison of clinical and biochemical features at baseline and I2-month follow-up within eachgroup and between them

\begin{tabular}{|c|c|c|c|c|c|c|c|}
\hline & \multicolumn{3}{|c|}{ Therapeutic Success } & \multicolumn{3}{|c|}{ Therapeutic Failure } & \multirow[t]{2}{*}{$p$} \\
\hline & Baseline & 12 months & $p$ & Baseline & 12 months & $p$ & \\
\hline BMI (Kg/m2) & $30.3 \pm 6.1$ & $31.4 \pm 6.8$ & 0.19 & $27.9 \pm 5.4$ & $29.1 \pm 5.3$ & $<0.001 *$ & 0.504 \\
\hline SBP $(\mathrm{mmHg})$ & $128.8 \pm 22.6$ & $135.3 \pm 2 \mid .4$ & 0.189 & $130.1 \pm 18.9$ & $140.5 \pm 26.2$ & $0.038^{*}$ & 0.789 \\
\hline $\mathrm{DBP}(\mathrm{mmHg})$ & $73.7 \pm 12.5$ & $77.0 \pm 10.3$ & 0.55 & $74.1 \pm 13.1$ & $72.3 \pm 13.7$ & 0.659 & 0.252 \\
\hline TGO (RR:|0-3| U/L) & $\begin{array}{l}23 \text { (IQR I8.5- } \\
34.5)\end{array}$ & $\begin{array}{l}25 \text { (IQR 20.0- } \\
31.0)\end{array}$ & $\begin{array}{l}0.837 \text { (IQR I7.0- } \\
37.0)\end{array}$ & $\begin{array}{l}19 \text { (IQR I7.0- } \\
37.0)\end{array}$ & 26 (IQR 19.0-36.0) & 0.569 & 0.800 \\
\hline
\end{tabular}


Table Continued....

\begin{tabular}{|c|c|c|c|c|c|c|c|}
\hline & \multicolumn{3}{|c|}{ Therapeutic Success } & \multicolumn{3}{|c|}{ Therapeutic Failure } & \multirow[t]{2}{*}{$p$} \\
\hline & Baseline & 12 months & $p$ & Baseline & 12 months & $p$ & \\
\hline TGP (RR:|0-3| U/L) & $\begin{array}{l}28.5 \text { (IQR I6.0- } \\
44.0)\end{array}$ & $\begin{array}{l}25 \text { (IQR I6.0- } \\
35.5)\end{array}$ & 0.981 & $\begin{array}{l}\text { I6.5 (IQR I3.5- } \\
36.0)\end{array}$ & 23 (IQR I5.0-29.5) & 0.536 & 0.406 \\
\hline GGT (RR:7-3I U/L) & $\begin{array}{l}48(I Q R 23.5- \\
78.5)\end{array}$ & $\begin{array}{l}29(I Q R \text { 19.0- } \\
66.5)\end{array}$ & 0.569 & $\begin{array}{l}27.5(\mathrm{IQR} \text { 16.0- } \\
51.0)\end{array}$ & 37(IQR 19.0-64.0) & 0.683 & 0.860 \\
\hline AF(RR: 30-I20U/L) & $\begin{array}{l}97(I Q R \text { 65.0- } \\
131.0)\end{array}$ & $\begin{array}{l}89(I Q R \text { 60.0- } \\
113.0)\end{array}$ & 0.182 & $\begin{array}{l}\text { 86.5(IQR 66.0- } \\
\text { I08.0) }\end{array}$ & $\begin{array}{l}\text { 86.5(IQR 72.0- } \\
\text { I04.0) }\end{array}$ & 0.53 & 0.827 \\
\hline $\begin{array}{l}\text { Total cholesterol } \\
(\mathrm{mg} / \mathrm{dL})\end{array}$ & $\begin{array}{l}\text { I55(IQR I40.0- } \\
207.0)\end{array}$ & $\begin{array}{l}\text { I } 57 \text { (IQR I26.5- } \\
207.5)\end{array}$ & 0.637 & $\begin{array}{l}\text { I53 (IQR I38.0- } \\
\text { I77.0) }\end{array}$ & $\begin{array}{l}\text { I68 (IQR I5I.0- } \\
\text { 195.0) }\end{array}$ & 0.081 & 0.487 \\
\hline HDL-C (mg/dL) & $\begin{array}{l}42 \text { (IQR 38.0- } \\
53.0)\end{array}$ & $\begin{array}{l}44.5 \text { (IQR 40.0- } \\
48.0)\end{array}$ & 0.109 & $\begin{array}{l}47 \text { (IQR 42.0- } \\
58.0)\end{array}$ & 57 (IQR 46.0-62.0) & $0.013^{*}$ & $0.002^{*}$ \\
\hline LDL-C (mg/dL) & $\begin{array}{l}91 \text { (IQR 72.5- } \\
\text { I22.5) }\end{array}$ & $\begin{array}{l}96 \text { (IQR 6I.0- } \\
\text { I I8.0) }\end{array}$ & 0.808 & $\begin{array}{l}78 \text { (IQR 63.0- } \\
99.0)\end{array}$ & $\begin{array}{l}89 \text { (IQR 70.0- } \\
\text { II } 3.0)\end{array}$ & 0.162 & 0.716 \\
\hline TG (mg/dL) & $\begin{array}{l}\text { I5I (IQR I28.0- } \\
227.0)\end{array}$ & $\begin{array}{l}\text { I3I(IQR I I3.0- } \\
208.0)\end{array}$ & 0.086 & $\begin{array}{l}\text { II8(IQR 78.0- } \\
\text { I69.0) }\end{array}$ & $\begin{array}{l}\text { I08(IQR 69.0- } \\
\text { I75.0) }\end{array}$ & 0.565 & 0.071 \\
\hline FPG (mg/dL) & $\begin{array}{l}207 \text { (IQR I34.5- } \\
263.5)\end{array}$ & $\begin{array}{l}\text { I } 58 \text { (IQR I26.5- } \\
251.5)\end{array}$ & 0.099 & $\begin{array}{l}\text { I4I (IQR II0.0- } \\
\text { I97.0) }\end{array}$ & $\begin{array}{l}\text { I72.5 (IQR I07.0- } \\
324.0)\end{array}$ & 0.322 & 0.662 \\
\hline HbAlc (\%) & $\begin{array}{l}\text { II.I (IQR I0.2- } \\
\text { I3.0) }\end{array}$ & 8.3 (IQR 7.6-9.I) & $<0.001 *$ & $\begin{array}{l}9.8 \text { (IQR 9.0- } \\
10.5)\end{array}$ & 9.5 (IQR 8.4-I0.7) & 0.923 & $0.001 *$ \\
\hline $\begin{array}{l}\text { Serum creatinine } \\
(\mathrm{mg} / \mathrm{dL})\end{array}$ & $\begin{array}{l}0.73 \text { (IQR 0.63- } \\
\mathrm{I} .23 \text { ) }\end{array}$ & $\begin{array}{l}0.72 \text { (IQR 0.56- } \\
\mathrm{I} . \mathrm{I} 2)\end{array}$ & 0.509 & $\begin{array}{l}0.75 \text { (IQR 0.63- } \\
\mathrm{I} .23 \text { ) }\end{array}$ & 0.78 (IQR 0.68-I.0) & 0.275 & 0.440 \\
\hline EUA (mg/L) & $\begin{array}{l}35.4 \text { (IQR 4.8- } \\
84.7)\end{array}$ & $\begin{array}{l}36.4 \text { (IQR 20.8- } \\
\text { 149.4) }\end{array}$ & 0.198 & $\begin{array}{l}\text { I0.9(IQR 4.4- } \\
69.0)\end{array}$ & 9.2 (IQR 5.0-4I.I) & 0.062 & 0.147 \\
\hline
\end{tabular}

Abbreviations: IQR, interquartil range; BMI, body mass index; SBP, systolic blood pressure; DPB, diastolic blood pressure; AST, aspartate aminotransferase; ALT, alanine aminotransferase; GGT, $\gamma$ - glutamyltransferase; AF, alkaline phosphatase; LDL-C, low density protein cholesterol; HDL-C, high density lipoprotein cholesterol;TG, triglycerides; HbA Ic, glycated haemoglobin; UAE, urinary albumin excretion.

*Statistically significant $(p<0.05)$

\section{Binary logistic regression mode}

The baseline characteristics which achieved statistical significance in the univariate analysis between the group of patients with therapeutic success and the group of patients with therapeutic failure were included in a binary logistic regression model as potential candidates for therapeutic success predictors of elective hospital admission of patients with DM and poor glycaemic control.

The results are shown in Table 4. Only baseline HbAlc $(\mathrm{OR}=2.07 ; 95 \% \mathrm{CI} 1.21-3.54 ; \mathrm{p}=0.008)$ and the previous diagnosis of dyslipidaemia $(\mathrm{OR}=18.03 ; 95 \% \mathrm{CI} 1.08-302.32 ; \mathrm{p}=0.044)$ were significant predictors of therapeutic success. Type of DM, duration of insulin therapy, neuropathy and dyslipidaemia didn't show statistical significance when adjusted for other included variables. HbA1c AUC showed good discriminating power $(\mathrm{AUC}=0.806$; 95\%CI 0.702 $0.909 ; \mathrm{p}<0.001)$. A baseline $\mathrm{HbA} 1 \mathrm{c} \geq 10.15 \%$ had a sensitivity of $81.3 \%$ but only a specificity of $61.8 \%$ in predicting the success of elective hospital admission of patients with DM and poor glycaemic control.

Table 4 Binary logistic regression analysis for prediction of therapeutic success after elective admission for DM with poor glycaemic control

\begin{tabular}{llll}
\hline Predictor & OR & $\mathbf{9 5 \% ~ C l}$ & $\mathbf{p}$ value \\
\hline Type of DM & 1.03 & $0.08-13.45$ & 0.982 \\
Years of insulin therapy & 0.92 & $0.81-1.04$ & 0.163 \\
Neuropathy & 0.37 & $0.06-2.45$ & 0.302 \\
Diabetic foot & 0.21 & $0.02-2.50$ & 0.216 \\
Dyslipidaemia & 18.03 & $1.08-302.32$ & $0.044^{*}$ \\
HbAlc & 2.07 & $1.21-3.54$ & $0.008^{*}$ \\
\hline
\end{tabular}

Abbreviations: OR, odds ratio; $\mathrm{Cl}$, confidence interval

*Statistically significant $(p<0.05)$

\section{Discussion}

Education is an essential and obligatory part of DM management After the diagnosis, it is crucial to transmit the information, which allows the patient to understand the disease and how to deal with its potential complications, as well as how to have an active role in treatment. Only with the right education about the disease, will the patient acquire knowledge and develop the necessary skills to feel 
motivated and confident in self-care and in maintaining a healthy lifestyle. ${ }^{2-4}$ However, with the increasing incidence of DM, physicians are required to see more patients in less time and the educational segment is sometimes discarded. It is mandatory to ensure access to health care systems for these at-risk patients, but it becomes difficult to warrant the quality of health care available to them. Unwittingly, health care providers tend to neglect or quickly discharge important information, compromising the physician-patient communication. This failure in communication reaches an even larger dimension when we are faced with a population scarce in literacy and practical skills. ${ }^{2,3}$

Elective hospital admission can be an effective strategy to ensure that DM education is adequately provided when the outpatient setting has failed. Having the patient in an inpatient environment allows the physician to have more time to pass on the necessary knowledge, to answer doubts, to demystify fears and beliefs and to train the practical skills essential for compliance. The potential benefits of inpatient diabetes education were showed by Healy SJ et al.. These authors conducted a retrospective 30-day analysis of 2265 patient and a 180day analysis of 2069 patient with diabetes admitted for reasons other than diabetes decompensation and found that patients who received inpatient diabetes education had a lower frequency of readmission within the follow-up time. ${ }^{5}$

However, to the more than 1.3 million euros expended on DM care in 2015, the high costs of a hospitalisation have to be added. ${ }^{1}$ Kuniss et al., ${ }^{6}$ conducted a prospective longitudinal study to assess the efficacy of a patient education programme for the optimisation of conventional insulin therapy in patients with T2DM in an inpatient and an outpatient setting. These authors showed that HbAlc improved similarly in both groups, with a decrease of $1.2 \%$ in the outpatient group and of $1.3 \%$ in the inpatient group at 1-year follow-up. Furthermore, they found a significant increase in self-monitoring of blood glucose, however, also without significant differences between the two groups.

Studies examining the clinical efficacy of different types of DM treatment models have shown the importance of treatment satisfaction, since greater satisfaction has been found to be correlated with higher rates of compliance and better clinical outcomes. ${ }^{7-9}$ Some authors found that having any diabetes-related complication was associated with lower satisfaction scores..$^{7-11}$ Biderman et al also noted that foot ulcers were associated with the lowest treatment satisfaction. ${ }^{7}$ Furthermore, they found that patients taking oral hypoglycaemic agents were more satisfied than those taking the same drugs plus insulin. ${ }^{7}$ In our univariate analysis, the presence of neuropathy or diabetic foot lesions seems to be associated with a lower probability of therapeutic success, possibly reflecting the lower treatment satisfaction of these patients.

Additionally, the majority of patients treated with a more intensive insulin regimen had a tendency for therapeutic failure, in contrast with patients without insulin therapy, having all achieved the proposed outcome. Regarding clinical outcomes, Gafvels \& Wändell found that $\mathrm{HbA1c}$ was the most important determinant associated with coping strategies. ${ }^{12}$ These authors showed that self-trust and problem focusing were negatively correlated with $\mathrm{HbA} 1 \mathrm{c}$ and, in contrast, fatalism was positively correlated with this clinical outcome. ${ }^{12}$ Similarly, Rose et al., ${ }^{13}$ found that active coping behaviour was the only psychological variable significantly linked with $\mathrm{HbAlc}$, and Turan et al found that coping was a good predictor of $\mathrm{HbA} 1 \mathrm{c}$ values. ${ }^{13,14}$ These results allow us to infer that patients with higher HbAlc values may be less able to manage the disease or to avoid the anxiety that it causes, revealing a lower capacity to adapt to self-care and, consequently, will be the ones that most benefit from elective hospital admission. In fact, an important part of DM care depends on the patient and his self-care knowledge. ${ }^{4}$ However, instruction in self-therapy can be largely influenced by health care providers, who must have the skills and the opportunity to effectively convey relevant information for the treatment and to successfully exert relevant changes in patient's behaviour by emotional illness-coping strategies. ${ }^{15}$ An inpatient setting can provide the necessary means to exert these educational and coping strategies. Nevertheless, it is important to notice that, in addition to the significant reduction of $\mathrm{HbAlc}$, improvement in other metabolic parameters was not observed.

This study has several limitations. Firstly, it is retrospective and, therefore, a selection bias is impossible to exclude. Moreover, only patients of the Endocrinology ambulatory centre were included and the sample number is limited. A longer follow-up time would have been useful to study possible therapeutic success predictors. Patient's treatment satisfaction was not recorded and assessed, which would have been interesting to include in the analysis.

Future research should address the assessment of elective hospital admission therapeutic success of DM and poor glycaemic control and its comparison with outpatient management of the disease, in order to understand if the potential benefits of inpatient care can outshine the costs associated with hospital admission.

\section{Conclusion}

To the best of the authors' knowledge, this work is pioneer in trying to identify predictors of elective hospital admission therapeutic success of patients with DM and poor glycaemic control. There seems to be a significant correlation between therapeutic success and baseline $\mathrm{HbAlc}$.

Further prospective economic impact studies should be done to evaluate and compare the cost-benefit of hospitalisation versus the cost of achieving better quality of outpatient services, for example, by hiring more physicians and extending the consultation time.

\section{Declarations}

\section{Conflict of interest: None.}

Ethical approval: All procedures performed in this study involving human participants were in accordance with the ethical standards of the institutional and/or national research committee and with the 1964 Helsinki declaration and its later amendments or comparable ethical standards.

\section{Informed consent: Patient's consent was obtained.}

Availability of data and materials: The datasets used and/or analysed during the current study are available from the corresponding author on reasonable request

Competing interests: The authors declare that they have no competing interests

Funding: This research did not receive any specific grant from any funding agency in the public, commercial or not-for-profit sector.

Authors' contributions: DM and AS collected and interpreted the data. DM wrote the manuscript. IF, RBS, MMC, AF, CN, JQ, JLC, PF e DC participated in the medical treatment and revised the manuscript. All authors read and approved the final manuscript.

Acknowledgements: Not applicable. 


\section{References}

1. National Diabetes Observatory of the Portuguese Society of Diabetology. Annual Report of the National Diabetes Observatory. 2016.

2. Tomky D. Diabetes education: looking through the kaleidoscope. Clin Ther. 2013;35(5):734-739.

3. American Association of Diabetes Educators. Position statement: standards for outcomes measurement of diabetes self-management education. Diabetes Educ. 2013;29:804-816.

4. KM Schreurs, DT de Ridder. Integration of coping and social support perspectives: implications for the study of adaptation to chronic diseases. Clin Psychol Rev. 1997;17(1):89-112.

5. Healy SJ, Black D, Harris C, et al. Inpatient diabetes education is associated with less frequent hospital readmission among patients with poor glycemic control. Diabetes Care. 2013;36(10):2960-2967.

6. Kuniss N, Muller UA, Kloos C, et al. Substantial improvement in HbA1c following a treatment and teaching programme for people with type 2 diabetes on conventional insulin therapy in an in- and outpatient setting. Acta Diabetol. 2018; 55(2):131-137.

7. Biderman A, Noff E, Harris SB, et al. Treatment satisfaction of diabetic patients: what are the contributing factors? Family Practice. 2009;26(2):102-108.

8. Finkel MI. The importance of measuring patient satisfaction. Empl Benefits J. 1997;22(1):12-15.
9. Bener A, Keskin FE, Kurtulus EM, et al. Essential parameters and risk factors of the patients for diabetes care and treatment. Diabetes Metab Syndr. 2017;11(Suppl 1):S315-S320.

10. Ken W, Koopmanshap MA, Stolk RP, et al. Health-related quality of life and treatment satisfaction inDutch patients with type 2 diabetes. Diabetes care. 2002;25(3):458-463.

11. Nicolucci A, Cucinotta F, Squatrito S, et al. For the QuoLITy Study Group. Clinical and socio-economic correlates of quality of life and treatment satisfaction in patients with type 2 diabetes. Nutr Metab Cardiovasc Dis. 2009;19(1):45-53.

12. Gafvls C, Wandell PE. Coping strategies in men and women with type 2 diabetes in Swedish primary care. Diab Res Clin Prac. 2006;71(3):280 289.

13. Rose M, Fliege H, Hildebrandt M, et al. The network of psychological variables in patients with diabetes and their importance for quality of life and metabolic control. Diabetes Care. 2002;25(1):35-42.

14. Turan B, Osar Z, Molzan Turan J, et al. The role of coping with disease in adherence to treatment regimen and disease control in type 1 and insulin treated type 2 diabetes mellitus. Diabetes Metab. 2002;28(3):186-193.

15. Clark CM. Reducing the burden of diabetes: the National Diabetes Education Program. Diabetes Care. 1998;2(Suppl 3):C30-C31. 